\title{
APPLICATIONS OF CONTEMPORARY DECISION-MAKING METHODS TO THE DEVELOPMENT OF ECONOMY AND TECHNOLOGY
}

\author{
Huchang LIAO $^{1,2}$, Zeshui $\mathrm{XU}^{1 *}$, Francisco HERRERA ${ }^{2,3}$ \\ ${ }^{1}$ Business School, Sichuan University, 610064 Chengdu, China \\ ${ }^{2}$ Andalusian Research Institute in Data Science and Computational Intelligence (DaSCI), \\ University of Granada, 18071 Granada, Spain \\ ${ }^{3}$ Faculty of Computing and Information Technology, King Abdulaziz University, \\ 21589 Jeddah, Saudi Arabia
}

In the past several decades, a lot of decision-making methods have been proposed, such as the AHP (Analytical Hierarchy Process), ANP (Analytic Network Process), TOPSIS (Technique for Order Preference by Similarity to Ideal Solution), VIKOR (VIsekriterijumska optimizacija i KOmpromisno Resenje), COPRAS (COmplex PRoportional ASsessment), MAUT (Multi-Attribute Utility Theory), MULTIMOORA (Multi-Objective Optimization on the basis of a Ratio Analysis plus the full MULTIplicative form), MACBETH (Measuring Attractiveness by a Categorical Based Evaluation THchnique), PROMETHEE (Preference Ranking Organization METHod for Enrichment of Evaluations), ELECTRE (ELimination Et Choix Traduisant la REalite, in French, ELimination and Choice Expressing the Reality), TODIM (an acronym in Portuguese of interactive and multi-criteria decision making) and GRA (Grey Relational Analysis). These classical decision-making methods have been extended into different contexts with uncertain information, such as interval numbers, fuzzy sets, intuitionistic fuzzy sets, interval-valued fuzzy sets, grey numbers, hesitant fuzzy sets, linguistic terms, hesitant fuzzy linguistic terms, probabilistic linguistic term sets, and so on. In addition, new decision-making methods, such as the BWM (Best Worst Method), GLDS (Gained and Lost Dominance Score) method, DNMA (Double Normalization-based Multiple Aggregation) method, SWARA (Stepwise Weight Assessment Ratio Analysis), WASPAS (Weight Aggregated Sum Product ASsessment), ARAS (Additive Ratio ASsessment), CoCoSo (Combined Compromise Solution), SMAA (stochastic multi-criteria acceptability analysis), and different scholars have regularly proposed the variations of these methods. These contemporary decision-making methodologies provide a variety of techniques to the development of economy and technology. The study on the applications of modern decision-

*Corresponding author. E-mail: xuzeshui@263.net 
making methods to the development of economy and technology has become promising in the past several years.

The special issue of Technological and Economic Development of Economy entitled "Applications of Contemporary Decision Making Methods to the Development of Economy and Technology" dedicates to exploring the evolving of contemporary decision-making methods and their applications in different aspects of modern society. After the reviewing process, five papers have been selected for publication in this special issue according to the review criterion on technical contributions. These papers provide exciting research results in the frontier of decision-making methodologies and their applications.

The first paper by Xiaomei Mi, Huchang Liao, Yi Liao, Qi Lin, Benjamin Lev, and Abdullah Al-Barakati, presents an SMAA-MULTIMOORA method by considering the advantages of SMAA in tackling uncertain information and MULTIMOORA in aggregating alternatives' utilities robustly. An application in green supplier selection regarding the economic, environmental and social criteria is presented.

The next paper, investigated by Juan-Juan Peng, Chao Tian, Wen-Yu Zhang, Shuai Zhang, Jian-Qiang Wang, defines the picture fuzzy exponential entropy to determine the weights of criteria of multi-criteria decision-making problems and then incorporates the VIKOR method with picture fuzzy information. An implication in sustainable supplier selection by using the approach is provided for sustainable supply chain management.

The third paper presented by Jie Gao, Zhilei Liang, Jennifer Shang and Zeshui Xu, studies a dual-channel recycling closed-loop supply chain and investigates the royalty strategy involving cost-reducing technique for remanufacturing patented products. Facing information asymmetry and market uncertainty, they address the problem where the patent licensor (manufacturer) and licensee (remanufacturer) simultaneously compete in the sales market and recycling market. The findings of this paper offer theoretical and methodological guidance for the implementation of patented technique royalty between manufacturing and remanufacturing companies. They can also provide evidence for relevant government departments to monitor and evaluate the implementation of remanufacturing companies in product recycling and remanufacturing.

The next paper, written by Amin Mahmoudi, Saad Ahmed Javed, Sifeng Liu and Xiaopeng Deng, attempts to rank Project Management Knowledge Areas based on their perceived importance using Deng's GRA model. They argue that the tradition of assigning 0.5 value to the model's distinguishing coefficient needs to be changed and to get convincing results from the model, it is better to perform sensitivity analysis by varying the value of the coefficient. Furthermore, comparative studies with two other MCDM methods - AHP and BWM - are presented.

Finally, Xunjie Gou, Zeshui Xu and Wei Zhou develop a multi-stage interactive consensus reaching algorithm to deal with multi-expert decision-making problem with linguistic preference orderings (LPOs). The main ideas of this paper are to define the new concept of LPOs, develop transformation models to transform each LPO into the corresponding double hierarchy linguistic preference relation with complete consistency and establish a multi-stage consensus optimization model. Additionally, some numerical examples are presented to illustrate the developed methods. 


\section{Acknowledgements}

We want to thank the three Editor-in-Chief of Technological and Economic Development of Economy, Professor Edmundas Kazimieras Zavadskas, Professor Jonas Šaparauskas and Professor Zenonas Turskis for their great support and kind help to achieve this special issue. We would also like to acknowledge all the reviewers for their support in the evaluation of the papers submitted to this special issue. 